\title{
Economic empowerment of rural women of Patiala through skill development and group dynamics
}

\author{
GURUPDESH KAUR
}

Received: 04.07.2017; Revised: 29.10.2017; Accepted: 13.11.2017

Author for Correspondence

GURUPDESH KAUR

Krishi Vigyan Kendra, PATIALA (PUNJAB) INDIA

Email : gurupdeshkaur@gmail.

com
DABSTRACT : Home science component of Krishi Vigyan Kendras organize skill development trainings under the aegis of ICAR throughout India for the upliftment of rural women. These trainings are geared towards the needs of rural women in a particular context keeping in view their social needs, culture and geographic realities. The present study was carried out to assess the economic empowerment of rural women of Patiala through skill development and group dynamics. One hundred and twenty four respondents participated in the study. Primary data were collected through interview schedule during the year 2016. Results reveal that about $80 \%$ of the respondents improved their skills in stitch and needle craft while $87 \%$ respondents contributed to family income. Seventy per cent respondents agreed that they have better leadership and communication skills after skill development. Findings indicated that organizing women into self-help groups was a relevant strategy for empowering them, as poor women demonstrated a strong tendency to derive strength from being a member of the group. The intervention of KVK had a positive impact on functional status of self help groups. Krishi Vigyan Kendra, Patiala was able to find a perfect fit between skills, resources available, technological options and marketing avenues.

KEY WORDS: Skill development, Group dynamics, Self-help groups, Rural women, Empowerment indicators

- HOW TO CITE THIS PAPER : Kaur, Gurupdesh (2017). Economic empowerment of rural women of Patiala through skill development and group dynamics. Asian J. Home Sci., 12 (2) : 565-569, DOI: 10.15740/ HAS/AJHS/12.2/565-569. 